\title{
Innovative training of university students in cardiac arrest in clinical Ssimulation
}

\section{Entrenamiento innovador de estudiantes universitarios en parada cardíaca en simulación clínica}

\author{
Nancy de los Angeles Segura-Azuara', Juan Carlos Hidalgo', Brenda Salvador', Elsie Vázquez Camacho', \\ Santiago Martín Albo', Mildred Vanessa López Cabrera ${ }^{1}$
}

\begin{abstract}
Introduction: Statistics show nowadays, bystanders provided Cardiopulmonary Resuscitation (CPR) in 40-46\% of all out-of-the-hospital cardiac arrests. Strategies must focus on specialized training for non-medical personnel. Engaging new generations in self-care depends on the development of new approaches to address the issue. The objective of this study was to assess the efficacy of an innovative training in CPR through the perception of the participants. Material and methods: This study considered a quantitative approach with a descriptive and correlational design. This study had a convenience sample of 103 participants from undergraduate programs in different disciplines: Engineering, Health, Law, and Design with participated voluntarily in the innovate training. To understand the efficacy of the innovative training data was collected of the participants through a self-assessment rubric. While participants were taken part in the training, an expert assessor was observing the performance and scored the procedure using a similar rubric. Both rubrics use a 5-point Likert scale to assess the level of agreement with each sentence. Results: Self-assessment results show that students excel on identifying if a patient has a pulse (mean=4.47) and if a patient is breathing (mean=4.52). The results of the expert assessment indicate a higher level of performance in hand positioning (mean=4.75) and compression-ventilation coordination (mean=4.77).

Discussion: These results are encouraging as participants gained confidence on basic procedures, the main challenges are still on skills that rely deeply on practice. Therefore, this training might need to be offered periodically, as any certification offered for health professionals. This study is a first attempt to design an innovative short term and effective training that universities can replicate to prepare their students for these life-saving skills.
\end{abstract}

Keywords: CPR; educational innovation; clinical simulation; non-health personnel.

\section{Resumen}

Introducción: Las estadísticas muestran que hoy en día los transeúntes realizan la reanimación cardiopulmonar (RCP) en el 40-46\% de las paradas cardíacas extrahospitalarias. Las estrategias deben centrarse en la formación especializada del personal no médico, por lo que es importante desarrollar; nuevos enfoques para abordar el tema y comprometer a las generaciones más jóvenes en el autocuidado. El objetivo de este estudio fue evaluar la eficacia de un entrenamiento innovador en RCP a través de la percepción de los participantes. Material y métodos: Se utilizó un diseño cuantitativo para correlacionar ambas medidas de rendimiento. Este estudio consideró un enfoque cuantitativo con un diseño descriptivo y correlacional. Este estudio tuvo una muestra de conveniencia de 103 participantes de programas de pregrado en diferentes disciplinas: Ingeniería, Salud, Derecho y Diseño con participación voluntaria en el entrenamiento innovador. Para entender la eficacia de la formación innovadora se recogieron datos de los participantes a través de una rúbrica de autoevaluación. Mientras los participantes participaban en la formación, un evaluador experto observaba la actuación y puntuaba el procedimiento utilizando una rúbrica similar. Ambas rúbricas utilizan una escala Likert de 5 puntos para evaluar el nivel de acuerdo con cada frase. Resultados: Los resultados de la autoevaluación muestran que los estudiantes destacan en la identificación de si un paciente tiene pulso (media=4,47) y si un paciente respira (media=4,52). Los resultados de la evaluación de expertos indican un mayor nivel de rendimiento en la colocación de las manos (media=4,75) y en la coordinación compresión-ventilación (media=4,77). Discusión: Estos resultados son alentadores, ya que los participantes ganaron confianza en los procedimientos básicos; los principales retos siguen siendo las habilidades que dependen en gran medida de la práctica. Por lo tanto, es posible que esta formación deba ofrecerse periódicamente, como cualquier certificación

(1) Tecnológico de Monterrey, Escuela de Medicina y Ciencias de la Salud Monterrey. Nuevo León, México.

Autor de correspondencia: nsegura@tec.mx 
ofrecida a los profesionales de la salud. Este estudio es un primer intento de diseñar una formación innovadora, eficaz y de corta duración, que las universidades pueden replicar para preparar a sus estudiantes en estas habilidades que salvan vidas.

Palabras clave: RCP; innovación educativa; simulación clínica; personal no sanitario.

Fecha de envío: 2021-05-28 - Fecha de aceptación: 2021-08-19

\section{Introduction}

Worldwide, cardiac arrest is a significant health problem estimated to cause $15-20 \%$ of all deaths (Böttiger et al., 2018). According to the American Heart Association, cardiac arrest is between 250,000 and 425,000 cases yearly from 2012 to 2016 in the US alone. In Europe, more than 700,000 people die from cardiac arrest (SCA Foundation, 2018). In the US, around $40-46 \%$ of out-of-the-hospital cardiac arrests (OHCA) received CPR by a bystander, with a survival rate of 9.5-12\% (Wissenberg et al., 2013). In other countries, bystander resuscitation rates reach levels above $60 \%$, and 15 to $20 \%$ of out-of-the-hospital cardiac arrests end with hospital treatment SCA Foundation, 2018).

One of the main factors related to survival is that it usually takes too long for the emergency medical service (EMS) to arrive at the scene after the victim collapses (Böttiger et al., 2018). The time the victim is pulseless is related to survival; even after 3-5 minutes of circulatory arrest, neurons start to die. Data about resuscitation rates are contradictory, with estimates ranging from 5 to $80 \%$ across the world; bystander immediate hands-on response is crucial for survival (Wissenberg et al., 2013). Several initiatives to increase bystander training in CPR included both in children and adults, such as "Kids Save Lifes" and "All citizens of the world can save a life" that have been effective in training individuals (Bohn et al., 2015).

\section{Definition and algorithm}

Cardiac arrest is the abrupt loss of heart function, it can come on suddenly or in the wake of other symptoms (Ramireddy \& Chugh, 2021). Pulse and blood pressure are lost instantaneously, followed by a loss of consciousness in a matter of seconds (Panhuyzen-Goedkoop et al., 2018). Not following the appropriate steps in the algorithm can result in death. In cardiac arrest, the likelihood of surviving declines by approximately $10 \%$ for every minute that it takes to start maneuvers; and can progress to irreversible biological death within 10 minutes (Eisenberg, 2013).

CPR and immediate use of a defibrillator may reverse cardiac arrest and restore normal heart rhythm. Up to $30 \%$ of normal blood flow can be achieved with good quality CPR, thus maintaining a small blood flow to the vital organs, particularly the heart and brain, which are the most sensitive to the lack of oxygen (Kornegay et al., 2018). CPR can allow the cardiac muscle to contract and restore a normal heart rhythm, which reduces the possibility of brain damage (Marino et al., 2018).

It is important to emphasize that CPR by itself gains time. On the other hand, defibrillation is curative; by simultaneously depolarizing all heart fibers, it allows the inherent pacemaker capacity of the heart to re-establish its rhythm. The sooner both CPR and defibrillation start, the better the outcome. We know that bystander CPR will double the survival rate and that early use of an automated external defibrillator can increase survival rates up to $75 \%$ in witnessed cardiac arrests (Alshahari et al., 2018).

\section{Training for CPR}

Research shows that the better bystanders can identify a cardiac arrest and perform the correct sequence in the procedure, the higher the success rate, leading to appropriate care for compromised patients. Learning a life-saving technique like CPR is no longer limited to health-related professionals (Alsharari et al., 2018). Bystanders usually have narrowed their participation in the event of cardiac arrest because they do not feel prepared to deal with the situation; therefore, formal training could benefit their inclusion (AI-Shaqsi et al., 2018). Training laypeople on using an AED during OHCA leads to increased survival (Callahan \& Fuchs, 2018).

Some high schools and universities have declared mandatory learning on how to perform CPR for their students. More than 30 states in the US have CPR training requisite for high school graduation (Callahan \& Fuchs, 2018). Alsharari et al. (2018) suggest that a 3-week course is effective in the final year of university, and as a result, it started to be a graduation requirement. Others advocate that training must be frequent to incorporate the new improvements in the clinical guidelines and agree that this type should be yearly for health-related colleges (Alsayil et al., 2016).

\section{Incorporation of simulation for training}

Although all training in CPR may represent an improvement in skills' assessments, the educational trends have suggested a shift towards active learning techniques, declaring the need to perform 
simulated scenarios to prepare participants to deal with the emotions and stress of life-threatening situations. Research has shown that demonstrating those procedures and receiving expert feedback is vital for skills improvement. Some studies have used self-assessment to measure performance in the correct technique, but they lack the opportunity to assess the procedures and maneuvers' sequence. Although some authors argue that self-assessment is of little value since there is frequently low consistency with the observed performance by experts, it has two main benefits (Davis et al., 2006). One, it consolidates learning by helping students to reflect on what they have learned in the light of previous experiences allowing the development of expertise and students' engagement in their learning as they start applying these assessment criteria consistently; and two, it helps in building on confidence about performance in real-life situations.

Using simulation for training has several advantages, including solving scheduling issues and appropriate case selection while avoiding risks in patient safety. Mundell (2013) argues that simulation-based scenarios benefit resuscitation training. The authors claim that this training is more effective than traditional approaches without simulation interventions for acquiring procedural skills. However, this does not have an impact on knowledge-based or speed-based assessment.

The objective of this study was to assess the efficacy of an innovative training in CPR through the perception of the participants.

\section{Material and methods}

This study considered a quantitative approach with a descriptive and correlational design for the analysis.

This study considered a convenience sample of 103 participants from undergraduate programs in different disciplines: Engineering, Health, Law, and Design with participated voluntarily in the innovate training.

To understand the efficacy of the innovative training data was collected of the participants through a self-assessment rubric. The self-assessment rubric evaluates the previous knowledge of the participant regarding CPR, out-of-hospital chain of survival, and use of AED. While participants were taken part in the training, an expert assessor was observing the performance and scored the procedure using a similar rubric. This rubric describes activating an emergency response system, appropriate placement of hands and arms for compressions, opening the airway, and starting proper ventilation. Both rubrics use a 5-point Likert scale to assess the level of agreement with each sentence proposed, where 1 stands for total disagreement and 5 for total agreement.

For the analysis, descriptive statistics were used to understand trends in every item. Afterward, the expert assessor score was contrasted with the self-assessment using Pearson correlation. The ranges used for the interpretation of the correlation were: weak (interval 0 to 0.25 ), low ( 0.26 to 0.50 ), high ( 0.51 to 0.75 ), and strong ( 0.76 to 1$)$. The last part of the analysis focused on assessing the educative impact of the program, therefore an assessment of the quality of CPR was conducted. This assessment focused in the participant achieving a chest compression depth $>5 \mathrm{~cm}$, chest compression rate 100-120/min, pre-shock pause $>10 \mathrm{sec}$, and chest compression fraction $>60 \%$.

As part of this innovative training for university students in cardiac arrest using clinical simulation, participants received a 4-hour workshop based on the guidelines on the American Heart Association (AHA) on basic CPR. The first part of the workshop consisted of a lecture to raise awareness of bystander engagement in medical emergencies and the technical aspects of CPR. After that, each student started practicing on an instrumented, auditory, and visual feedback on rate and depth of compression mannequin while on a clinical simulation scenario from the AHA manuals about an adult cardiopulmonary arrest. Later, they formed teams of four to practice CPR performed by 1 and 2 rescuers. This training consisted of basic life support (BLS) for lay rescuers: Assessment, EMS activation, the ABCs for CPR, and defibrillation. They were then assessed by a medical expert in the current AHA guidelines on BLS for lay rescuers, using the procedural assessment rubric. The expert provided feedback on performance to the student.

\section{Results}

The sample consisted of $49 \%$ female and 51\% male participants. Self-assessment results show that students excel on: identifying if a patient has a pulse (mean of 4.47) and if a patient is breathing (mean of 4.52). 
Table 1: Self-assessment of participants.

\begin{tabular}{|c|c|c|c|}
\hline Criterion & Item & Mean & Standard deviation \\
\hline \multirow[t]{4}{*}{ Preparation procedures } & The participant assesses scene safety (self-safety and patient safety). & 3.98 & 0.64 \\
\hline & The participant identifies the level of consciousness. & 4.34 & 0.62 \\
\hline & Activates Emergency Medical Services (EMS) & 4.16 & 0.73 \\
\hline & Total: & 4.16 & 0.66 \\
\hline \multirow[t]{4}{*}{ Cardiac compressions } & The participant places both hands on the sternal bone, one on top of the other. & 4.75 & 0.47 \\
\hline & The participant keeps his/her arms in a straight position to start compressions. & 4.63 & 0.54 \\
\hline & The participant starts compressions promptly. & 4.67 & 0.5 \\
\hline & Total: & 4.68 & 0.50 \\
\hline \multirow{3}{*}{$\begin{array}{l}\text { Coordination with ven- } \\
\text { tilation }\end{array}$} & The participant starts ventilation. & 3.93 & 0.67 \\
\hline & The participant coordinates compressions and ventilation adequately. & 4.77 & 0.42 \\
\hline & Total: & 4.35 & 0.545 \\
\hline Pulse & The participant assesses pulse (determines if it is absent). & 4.67 & 0.47 \\
\hline Airway and breathing & The participant opens the airway and removes obstruction if visible. & 3.98 & 0.61 \\
\hline \multirow[t]{3}{*}{ AED Defibrillator } & The participant installs the AED correctly on the patient upon arrival. & 4.65 & 0.47 \\
\hline & The participant follows the AED instructions adequately. & 4.63 & 0.48 \\
\hline & Total: & 4.64 & 0.475 \\
\hline \multirow[t]{3}{*}{ After CPR } & The participant re-starts compressions. & 4.24 & 0.76 \\
\hline & The participant re-starts ventilation. & 3.82 & 0.82 \\
\hline & Total: & 4.03 & 0.79 \\
\hline
\end{tabular}

The results of expert competence assessment indicate a higher

level of performance in hand positioning and compression-ventilation coordination.

Table 2: Experts' procedural assessment of participants.

\begin{tabular}{|c|c|c|c|}
\hline Criterion & Item & Mean & Standard deviation \\
\hline \multirow[t]{4}{*}{ Preparation procedures } & The participant assesses scene safety (self-safety and patient safety). & 3.98 & 0.64 \\
\hline & The participant identifies the level of consciousness. & 4.34 & 0.62 \\
\hline & The participant activates Emergency Medical Services (EMS) & 4.16 & 0.73 \\
\hline & Total: & 4.16 & 0.66 \\
\hline \multirow[t]{4}{*}{ Cardiac compressions } & The participant places both hands on the sternal bone, one on top of the other. & 4.75 & 0.47 \\
\hline & The participant keeps their arms straight to start compressions. & 4.63 & 0.54 \\
\hline & The participant starts compressions promptly. & 4.67 & 0.50 \\
\hline & Total: & 4.68 & 0.50 \\
\hline \multirow{3}{*}{$\begin{array}{l}\text { Coordination with ven- } \\
\text { tilation }\end{array}$} & The participant starts ventilation. & 3.93 & 0.67 \\
\hline & The participant coordinates compressions and ventilation adequately. & 4.77 & 0.42 \\
\hline & Total: & 4.35 & 0.55 \\
\hline Pulse & The participant assesses pulse (determines if it is absent). & 4.67 & 0.47 \\
\hline Airway and breathing & The participant opens the airway and removes obstruction if visible. & 3.98 & 0.61 \\
\hline \multirow[t]{3}{*}{ AED Defibrillator } & The participant installs the AED correctly on the patient upon arrival. & 4.65 & 0.47 \\
\hline & The participant follows the AED instructions. & 4.63 & 0.48 \\
\hline & Total: & 4.64 & 0.47 \\
\hline \multirow[t]{3}{*}{ After CPR } & The participant re-starts compressions. & 4.24 & 0.76 \\
\hline & The participant re-starts ventilation. & 3.82 & 0.82 \\
\hline & Total: & 4.03 & 0.79 \\
\hline
\end{tabular}


A correlation between self-assessment and expert performance assessment showed a weak correlation on the following elements:

Table 3: Comparison between self-assessment and experts' assessments.

\begin{tabular}{|c|c|c|c|}
\hline Criterion & Self- assessment & Expert & Correlation \\
\hline Preparation procedures & - & 4.16 & - \\
\hline Cardiac compressions & 4.19 & 4.68 & -0.02 \\
\hline Coordination with ventilation & 4.05 & 4.35 & 0.05 \\
\hline Pulse & 4.47 & 4.67 & 0.22 \\
\hline Airway and breathing & 4.52 & 3.98 & -0.2 \\
\hline AED Defibrillator & 4.37 & 4.64 & -0.16 \\
\hline After CPR & 4.04 & 4.03 & -0.04 \\
\hline
\end{tabular}

To assess the educative impact of the program, a quality assessment of CPR was conducted. This analysis shows overall high scores (table 4); with the highest achievement pulse and airway and breathing (Table 3). in reasonable compression rate, pre-shock pause, chest compression depth, and chest compression fraction were in descending order.

Table 4: Analysis of CPR Quality.

\begin{tabular}{lll}
\hline Criterion & Accuracy \% & Standard deviation \\
\hline Chest compression depth $\geq 5 \mathrm{~cm}$ & 93.2 & 0.43 \\
\hline Chest compression rate $100-120 / \mathrm{min}$ & 96.2 & 0.44 \\
\hline Pre-shock pause $\geq 10 \mathrm{sec}$ & 94.4 & 0.66 \\
\hline Chest compression fraction $>60 \%$ & 92.6 & 0.42 \\
\hline
\end{tabular}

\section{Discussion}

From the results obtained from self-assessment, we can extract that the participants perceive that they know the theoretical CPR procedure; since they remember the steps before using a defibrillator and the appropriate hand placement before starting compressions and ventilation. Nevertheless, they seem unsure about performing cardiac compressions and placing the victim in the recovery position. Some authors have proposed that self-assessment is inaccurate, while others advocate for its use, with good results (Anderson et al., 2017; Weston et al., 2018). According to the expert's assessment, the participants were proficient in hand placement and the compression procedure. However, they were not able to perceive when to start and re-start compressions and ventilation. Although this would depend on the specific context they would be required to perform; participants would benefit from using clinical simulation to experience multiple similar cases and feel self-confident.

The weak correlation we found between self and expert's assessment in this study is consistent with other researchers (Davis et al., 2006). Repetition of the training practice results in reducing the gap in scores as students evolve from novice to expert. In this research, experts found a higher level of performance than that perceived by students, which points to students' high level of exigence compared to experts' assessment. Providing multiple feedback sessions for each practice session could help students build confidence for their performance in real-life settings. Still, CPR quality analysis results showed high scores, demonstrating the technique's effectiveness in this population.

As any intervention, this study has several limitations. The first one has to do with the sample considered as only participants from a single institution and one country participated in the study. Therefore, results might not be representative of other populations. The participants were undergraduate students then the success of this strategy might be limited to a youth and young adult population, and the application of the intervention in other communities may be approached with caution. As part of the analysis, we did not consider an assessment before the intervention, so we could not contrast performance categorizing prior knowledge on CPR. Future studies might approach the need to understand the effect of formal trainings or informal approaches such as movies or tv shows in the preparation of lay personnel. 


\section{Conclusion}

With statistics showing that $40-46 \%$ of out-of-the-hospital cardiac arrests received CPR by a bystander, there is a critical need to implement strategies for training everyone. Training non-medical personnel in CPR techniques is beneficial to face the cardiac arrest health problem worldwide. These results are encouraging as the participants gained confidence on basic procedures, the main challenges are in identifying the moment to start or finish the compressions; however, these skills rely deeply on practice. Therefore, this training might need to be offered periodically, as any certification offered for health professionals. This study is a first attempt to design an innovative short term and effective training that universities can replicate to prepare their students for these life-saving skills. Several techniques could improve the appropriation of the algorithms and procedures of CPR, analyzing the effectiveness of this innovative training for university-level students could improve the quality of teaching methods to target specific groups using clinical simulation.

\section{Sources of financing}

None.

\section{Contributions and conflicts declared by the authors}

NASA: conceptualization, methodology, analysis, project management, review, and editing of the final manuscript.

$\mathrm{JCH}$ : field research, analysis, writing of the first manuscript. BS: field research, analysis, writing of the first manuscript. EV: field research, analysis, writing of the first manuscript. SA: field research, analysis, writing of the first manuscript. ML: field research, analysis, project management, review, and editing of the final manuscript.

The authors declare that they have no conflicts of interest.

\section{References}

Alsayil SN, Alzahran SM. \& Alhawiti WM. (2016). Awareness of basic life support among medical and nursing students at Tabuk University. Basic Research Journal of Medicine and Clinical Sciences 5, 53-57.

Al-Shaqsi S, Al-Risi A. \& Al-Kashmiri A. (2018). Do laypeople in Oman know how to perform cardiopulmonary resuscitation? Oman Medical Journal 33, 178-179.

Alsharari AO, Alduraywish A, Al-Zarea EA, Salmon NI. \& Sheikh MSA. (2018). Current status of knowledge about cardiopulmonary resuscitation among university students in the Northern region of Saudi Arabia. Cardiology Research and Practice 2018,1-9.
Andersson D, Rankin A. \& Diptee D. (2017). Approaches to team performance assessment: a comparison of self-assessment reports and behavioral observer scales. Cogn Technol Work 19, 517-528.

Bohn A, Lukas, R, Breckwoldt J, Böttiger BW. \& Van Aken H. (2015). Kids save lives: why schoolchildren should train in cardiopulmonary resuscitation. Curr Opin Crit Care 21, 220-225.

Böttiger BW, Lockey A, Aickin R, Castren M, de Caen A, Escalante R, Kern KB, Lim SH, Nadkarni V, Neumar RW, Nolan JP, Stanton D, Wang TL. \& Perkins GD. (2018). “All citizens of the world can save a life" - The World Restart a Heart (WRAH) initiative started in 2018. Resuscitation 128, 188-190.

Callahan JM. \& Fuchs SM. (2018). Advocating for life support training of children, parents, caregivers, school personnel, and the public. Pediatrics 141

Davis DA, Mazmanian PE, Fordis M, Van Harrison R, Thorpe KE. \& Perrier L. (2006). Accuracy of Physician Self-assessment Compared With Observed Measures of Competence. JAMA 296,1094-1102.

Eisenberg MS. (2013). Resuscitate!: how your community can improve survival from sudden cardiac arrest. University of Washington Press. Kornegay JG, Von Foerster N, Laurie A, \& Daya M. (2018). Does Accelerometer Use Lead to Higher Quality CPR for Advanced Cardiac Life Support Providers? A Prospective Randomized Study. Eurasian Journal of Emergency Medicine 17, 153.

Marino BS, TabbuttS, MacLaren G, Hazinski MF, Adatia I,Atkins DL, Checchia P, DeCaen A, Fink EL, Hoffman GM, Jefferies JL, Kleinman M, Krawczesky CD, Licht DJ, Macrae D, Ravishankar C, Samson RA, Thiagarajan RR, Toms R, Tweddell J. \& Laussen PC. (2018). Cardiopulmonary resuscitation in infants and children with cardiac disease: a scientific statement from the American Heart Association. Circulation 137, e691-e782.

Mundell WC, Kennedy CC, Szostek JH, \& Cook DA. (2013). Simulation technology for resuscitation training: A systematic review and meta-analysis. Resuscitation 84, 1174-1183.

Panhuyzen-Goedkoop NM, Wellens HJ. \& Piek JJ. (2018). Early recognition of sudden cardiac arrest in athletes during sports activity. Neth Heart J 26, 21-25.

Ramireddy A. \& Chugh SS. (2021). Do peak times exist for sudden cardiac arrest. Trends in Cardiovascular Medicine 31, 172-176.

SCA Foundation. (2018). AHA releases the latest statistics on sudden cardiac arrest | Sudden Cardiac Arrest Foundation. Available at. Accedido en: http://www.sca-aware.org/sca-news/aha-releases-latest-statistics-on-sudden-cardiac-arrest el 8 de octubre de 2018. 
Segura et al.

Weston BW, Jasti J, Mena M, Unteriner J, Tillotson K, Yin Z, Colella R. \& Aufderheide TP. (2019). Self-Assessment Feedback Form Improves Quality of Out-of-Hospital CPR. Prehospital Emergency Care 23, 66-73.
Wissenberg M, Lippert FK, Folke F, Weeke P, Hansen CM, Christensen EF, Jans H, Hansen PA, Lang-Jensen T, Olesen JB, Lindhardsen J, Fosbol EL, Nielsen SL, Gislason GH, Kober L \& Torp-Pedersen C. (2013). Association of national initiatives to improve cardiac arrest management with rates of bystander intervention and patient survival after out-of-hospital cardiac arrest. JAMA 310,1377-1384. 